\title{
Understanding Aspects of the Theory of Evolution Using Paleontology
}

\section{Kouzas $\mathrm{D}^{1}$ and Athanasiou $\mathrm{K}^{2 *}$ \\ ${ }^{1}$ Teaching Natural Sciences, Geologist, Computer Science and Telecommunications, Greece}

${ }^{2}$ Biological and Health Education, University of Athens, Greece

\section{Research Article}

Volume 2 Issue 1

Received Date: January 31, 2019

Published Date: February 25, 2019

*Corresponding author: Kyriacos Athanasiou, National and Kapodistrian University of Athens, 13a Navarinou str., Athens 10680, Greece, Tel: 30-210-6930354; Email: kathanas@ecd.uoa.gr

\section{Abstract}

The need to strengthen the teaching of the Theory of Evolution through Natural Selection (TENS) is undoubted, as it has so far been taught in a fragmented way, without any emphasis on its unifying role. Non-formal environments such as the Science Museums can be used to enhance its teaching. In order to check-out whether the level of understanding TENSrelated concepts might increase, and whether the knowledge of the History of the Earth that has been acquired, together with changes that have been made to the students' interpretations of evolutionary problems, can contribute to understanding TENS acceptance and knowledge, a program of visits was planned for high school students in appropriate museums. These visits, offered to students a learning environment that included a variety of exhibits, such as real fossils and multimedia simulations on the history of Earth aiming to familiarize them with the evidence of Evolution. For this reason, paleontology museums qualified as ideal places to visit. The survey that was followed showed a reduction in their creationist reasoning. However, intuitive reasoning was proved to be rigid, as we have not observed some noticeable increase in the evolutionary reasoning. The degree of understanding concepts related to evolution, such as the importance of fossils, environmental changes and mass extinctions, has improved. Finally, the acquisition of knowledge about the relative age of species and about major geological and biological events in the Earth's History, has shown improvement, as well.

Keywords: Evolution Theory; Teaching; Science Museums; Fossils

Abbreviations: TENS: Theory of Evolution through Natural Selection; ER: Evolutionary Reasoning; IR: Intuitive Reasoning; CR: Creationist reasoning.

\section{Introduction}

The Theory of Evolution through Natural Selection (TENS) is the central theory that unifies all areas of biology [1] and is undoubtedly the most important concept of modern biology [2]. Nevertheless, the teaching of the TENS as it is often presented in the school class as another issue among many others, seems to be problematic, since it is leading to the false impression that it can be teached in isolation or even be overtaken or taught on the road [3]. Thus, it seems very probable, that this lack of proper evolutionary education may be 


\section{International Journal of Paleobiology \& Paleontology}

correlated to the low acceptance of Evolution in several societies. This seems to be the case at least for the Greek society which is possessing one of the lower positions on the evolutionary acceptance scale proposed by Miller, et al. [4], being only a few positions above USA and Turkey in rank [5]. There is also evidence of a weak negative correlation between religion and acceptance of the TENS [6].

Research shows that there are serious obstacles that make it difficult to understand and ultimately accept the TENS [7]. References to TENS, for example, in Primary Education are usually minimal and intuitive interpretations are not dealt with and sometimes they even become rather legitimate. These perceptions are so resilient that it is very difficult to be replaced in a later period of life [8]. All this and others, as it has already been stated, lead to a situation in which students cannot easily distinguish the different uses of concepts related to the process of Evolution, such as the case of adaptation, and this difficulty explains their tendency to express Lamarckian views [9].

For all the above mentioned reasons we decided to provide a Middle School classroom with access to real evidence of how Biological Evolution works. The basic idea was to guide students to examine real fossils via educational visits into appropriate Museums in order to they come in contact with footprints of lost species or others who survived as a result of adaptation. Research, on students who visited Natural History Museums, shows that they have more positive experiences when they actively participate in the process [10]. Cognitive progress of students has been shown to be obtained when there is a link between such visit and the curriculum. And when the ability to follow their own desired path within the showroom is provided to them along with the ability to work together in small groups, and finally, when the escort teachers are very well informed about the topic of the exhibition and are willing to share this information with their students [11].

\section{Methodology}

\section{Research Questions - Assumptions}

The present study was aiming to check whether and to what degree students' visits to appropriate museums can increase their knowledge about concepts related to TENS and help them to shape or adopt evolutionary interpretations instead of intuitive or creationist ones. Previous surveys have shown that a single visit to an interactive show about Evolution can positively influence, through a gradual increase in their understanding, attitudes of visitors towards the concept of evolution, regardless of beliefs, interests, or the age of the visitor [12]. Therefore the main question that was of interest to answer was to what extent a program of visits for 15year-old students, in a suitable museum, facilitates understanding of the TENS. The research hypotheses that were examined were whether the visits to appropriate museum environments:

a) Help in the acquaintance of concepts that contribute to understand Evolution; such as the importance of fossils, the relative age of rocks, environmental variability and the extinction of organisms through time.

b) Provide insights into the history of the Earth and the absolute age of important events in its history.

c) Cause a change in students' interpretations of Evolution issues.

\section{The Visiting Places}

The pupils of our study, had the opportunity to visit three places of interest, related to Paleontology and Evolution: 1. the Museum of Paleontology of Milia in Grevena, W. Macedonia, Greece. An area where there have been found the remains of the Pliocene mammoth Mammut borsoni [13]. 2. The Environmental Education Center of Grevena, which is a center affiliated to the museum of Milia, and 3. The Anthropological Museum and the Museum of Paleontology and Geology of the University of Athens.

\section{The Visits}

The first visit with the participation of 46 students (Group 1: $\mathrm{N}=21$ and Group 2: $\mathrm{N}=25$ ) was held at the Environmental Education Center of Grevena where the students attended the one-day program named "Geological Heritage - Fossils". The students initially attended a presentation that discussed geological time, geological history of the Earth, ways of fossilization and the importance of fossils, environmental changes, and a brief presentation of the history of the excavations in the area that led to the discovery of the findings which are located at the Museum of Palaeontology of Milia in Grevena. There the students came in contact with the findings of the excavations with the most spectacular $r$ exhibit being the $5.02 \mathrm{~m}$ tall tusk of the 3 million years mastodon Mammut borsoni. During the second visit to Athens with 25 students participating (Group 2: $\mathrm{N}=25$ ), they had the opportunity to visit the Anthropological Museum, the Museum of Palaeontology and Geology and the Museum of Mineralogy and Petrology at the 


\section{International Journal of Paleobiology \& Paleontology}

University of Athens. Also at the Planetarium of the Eugenides Foundation in Athens, students attended the screening "The Mystery of Life".

\section{The Research Plan}

This research project concerns the exposure of the experimental group to the dependent variable (visits) and the measure of the learning outcomes (independent variable). The methodological approach of this research follows the experimental example, but it is characterized as quasi-experimental research as there is no control by the researcher, neither on what exactly the sample will be nor on the exact time when the sample will be exposed to the dependent variable [14]. The main advantage over a purely experimental plan is that quasi-experiments are carried out in real-life conditions in real educational environments [15].

Following the usual symbolism for the representation of research projects [16], Table $1 \mathrm{X}$ represents the exposure of a group to the dependent variable (event) whose effects are to be measured. 0 refers to the measurement process and the present research plan is graphically illustrated in the following figure:

\begin{tabular}{|c|c|c|c|c|c|}
\hline Experimental Group 2 & $\mathrm{O}_{1}$ & $\mathbf{x}_{1}$ & $\mathrm{O}_{2}$ & $\mathbf{x}_{2}$ & $\mathrm{O}_{3}$ \\
\hline Experimental Group 1 & $\mathrm{O}_{1}$ & $\mathbf{x}_{1}$ & $\mathrm{O}_{2}$ & & $\mathrm{O}_{3}$ \\
\hline Control Group 0 & $\mathrm{O}_{1}$ & & $\mathrm{O}_{2}$ & & $\mathrm{O}_{3}$ \\
\hline
\end{tabular}

Table 1: Description of research project.

$\mathrm{X} 1$ : the first visit, $\mathrm{X} 2$ : the second visit.

01 : pre measurement of all the questions B1-8, G1-4.

02 : post measurement of the questions B1-7 and G1, intermediate measurement for B8.

03 : post measurement of the questions G1-4, post measurement for B8.

\section{Participants}

The sample of the survey consisted of 68 students in the 3rd grade of the regional high school of Karditsa in Greece. The separation of the students into groups was considered after their participation in the visits. As a result three groups emerged (Figure 1).

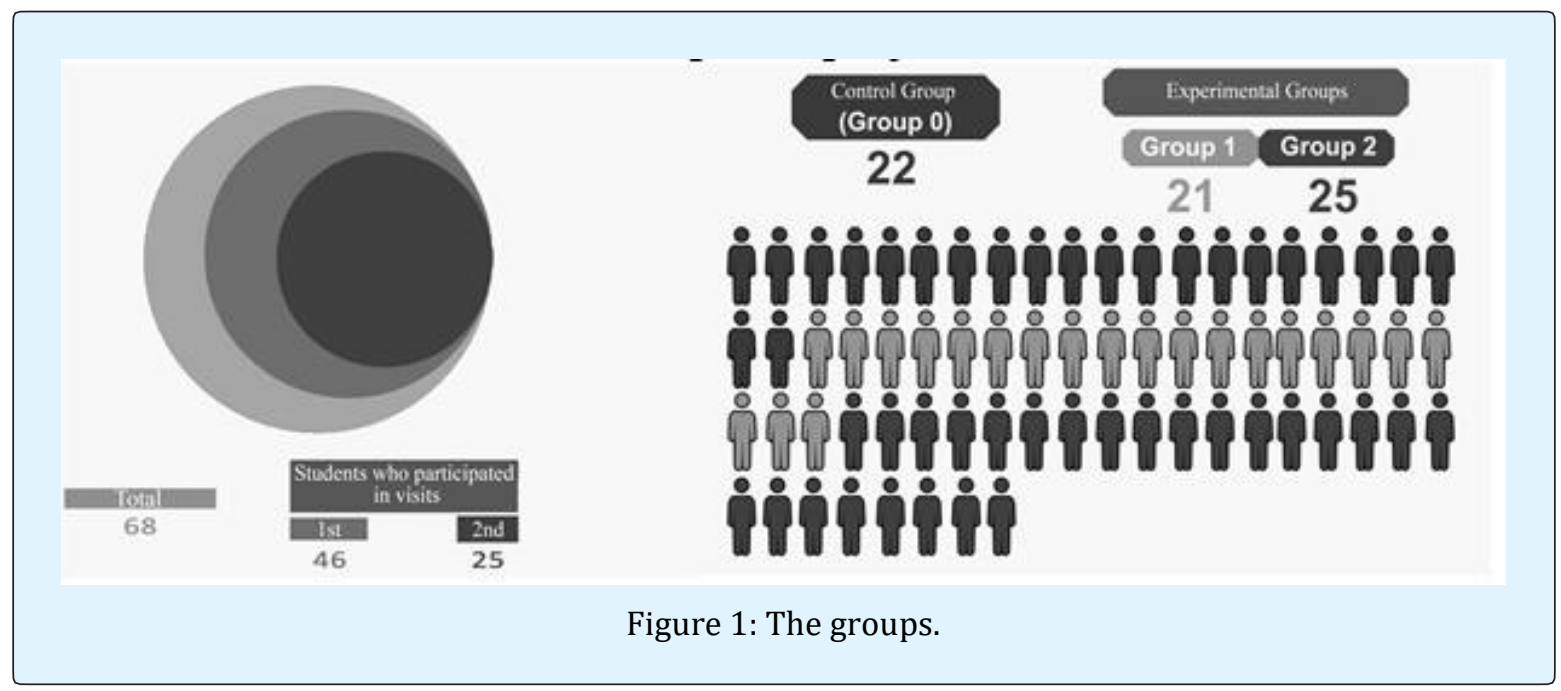

The first team (group 0) consisted of 22 students who did not participate in any visit, the second group (group 1) of 21 students who only participated in the first visit and the third group (group 2) of 25 students who participated in both visits.

\section{The Research Tool}

The questionnaire used can be divided into three parts. The first part concerns the fossils and layers of rocks. The design of this section was based on relevant research on the acceptance of TENS [1,17] and other research which proposes a stratigraphic column and seeks conclusions and results about the relative dating of the fossils - rocks, the importance of fossils, the mass extinction of organisms, the paleo-environment and the nature of science [18-20]. There were 5 layers in the column and there were fossil images in each layer. Seven suggestions - statements (B1-B7) accompanied the column and in these statements the students could choose the level of their agreement or disagreement with the help of a 5level Likert scale. The aim of the statements was to evaluate the knowledge and understanding of concepts such as the relative age of fossils and rocks (questions B1, 


\section{International Journal of Paleobiology \& Paleontology}

B2), the importance of fossils (questions B3, B5, B7), environmental variability (question $B 4$ ) and the extinction of species (Questions B5, B6, B7).

The second part contains question B8 which has been modelled in similar research papers [20]. This question requires from students to place seven major geological and biological events in a timeline starting from 15 billion years ago until today. The seven events that were given in random order were as follows: 1 .The beginning of the Universe, 2. The formation of the Earth, 3. The appearance of Life on Earth, 4. The appearance of the first fish, 5.The first plants on the land, 6.Extinction of dinosaurs, 7. First modern human (Homo Sapiens). The students' answers were scored in two ways. (a) Positioning accuracy of an event ( 5 points for correct positioning, 4 for deviation \pm 1 and so on). Thus, for the seven events, a cumulative scale with a maximum of 35 was created. (b) The correct sequence of placements where each event would receive a point if it was in the correct order (no matter the chronological placement) in relation to the events before and after it. This created a scale for all events with a maximum of 7 .

The third part of the questionnaire contains four scenarios (C1 to C4) where a phenomenon, an observation or an event is presented, and it is necessary to state the degree of agreement or disagreement with five justifications that accompany each text. The students were asked to state the degree of agreement or disagreement with these justifications using a 5-level Likert scale. The five explanations for each text are drafted in such a way that they represent either Evolutionary reasoning (ER), Intuitive reasoning (IR), or Creationist reasoning (CR). For evolutionary interpretations (ER) in the justifications, either the term "evolution" and its derivatives is explicitly referred to, or the concept of natural selection is described (i.e. organizations with adapted characteristics are more likely to survive), or reference is made to the role of mutations for speciation, or reference is made to a common ancestor of two distinct species. For the intuitive interpretations (IR) in the justifications, it is either implied that organizations are changing for some purpose (that is, adapted to the basis of a need), or a desire is expressed, a conscious effort to change, or that the new species always existed (either in the same space or in another remote area) but we had not previously noticed them. For creative interpretations (CR) in the justifications it is stated that each species was originally and initially created the way it is, or that it was designed specifically for the environment where it lives. In each scenario there are two evolutionary interpretations, two intuitive and one creative. The scenarios and the corresponding justifications were based on previous research papers [12,21-24]. The first scenario (C1) concerned the disappearance of the mastodon with regard to the observation that there are currently only two related species (the Asian and the African elephant); scenario C2 concerned the resistance that many microbes have acquired against antibiotics; $\mathrm{C} 3$ refers to the origins of the many different species of flies currently present in Hawaii and where they originated from; finally C4 refers to the observation of similarities between the human DNA and that of the chimpanzee. The total justifications that students were asked to agree or disagree with using the 5 -step Likert scale reaches twenty (five justifications for each of the four scenarios).

\section{Reliability of the Tool}

For the first part of the questionnaire, Cronbach's $\alpha$ test was conducted for all students during the pre-test. The calculation of $\alpha$ for all questions was low and this led to an analysis of factors and the grouping of the final seven into three factors (F1: Questions B1, B2 and B4, F2: Questions B3 and B7, F3: Questions B5 and B6). For the third part, Cronbach's $\alpha$ was measured for each of the three types of justification offered in each of the four scenarios (C1 to C4) (Table 2).

\begin{tabular}{|c|c|c|c|c|c|c|}
\hline \multirow{3}{*}{ Cronbach's Alpha } & F1 & F2 & F3 & \multicolumn{3}{|c|}{ C1,C2,C3,C4 } \\
\cline { 2 - 7 } & $(\mathrm{B} 1, \mathrm{~B} 2, \mathrm{~B} 4)$ & $(\mathrm{B} 3, \mathrm{~B} 7)$ & $(\mathrm{B} 5, \mathrm{~B} 6)$ & $\mathrm{ER}$ & $\mathrm{IR}$ & CR \\
\cline { 2 - 7 } & 0,753 & 0,697 & 0,702 & 0,685 & 0,652 & 0,637 \\
\hline
\end{tabular}

Table 2: Cronbach's $\alpha$.

It is obvious that the results are marginally reliable since the credibility factor $\alpha$ must be greater than 0.7 in order to have a reliable scale, [25]. For the second part, the control group's (group 0) answers were compared in the three (pre-intermediate - post) measurements in question B8 with the ANOVA analysis which showed that there are no statistically significant differences neither for positioning accuracy $F(2.63)=0.073$, Sig. $=0.930>5 \%$, nor for the correct order of placement between the three measurements of B8 for the control group, $F(2.63)=$ 0.638 , Sig. $=0.532>5 \%$ (Figure 2). 


\section{International Journal of Paleobiology \& Paleontology}

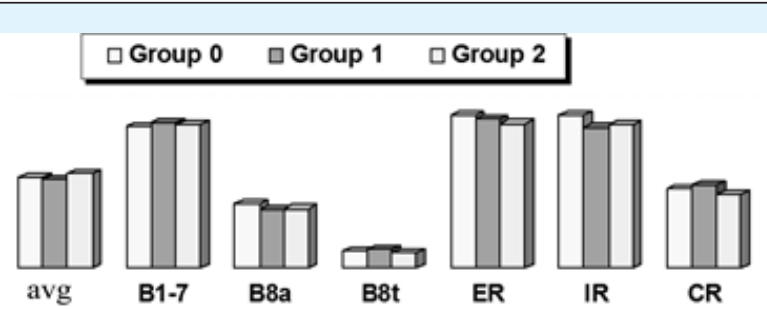

Figure 2: School performance and comparison of team scores in the pre-test for each section of the questionnaire.

avg: average school performance

B1-7: questions B1-7

B8a: question B8 positioning accuracy

B8t: question B8 correct order

ER: Evolutionary reasoning

IR: Intuitive reasoning

CR: Creationist reasoning

The groups formed were equivalent in the sense that they also had a comparable average score in the school score (overall annual average) and similar results in the pre-test 11.

\section{Results}

For the comparison of the groups, either the parametric t-test (for comparison of two tests or two groups) or the simple ANOVA dispersion analysis (for comparison of three tests or three groups) were used in which either the assumptions of normality and homogeneity of the dispersion were proved or the corresponding non-parametric tests were satisfying. In order to compare the pre and posttests, students were randomly assigned three-digit numbers and noted them on the questionnaire.

For the first part of the questionnaire and based on the grouping that resulted from the factors analysis that preceded, the scores of the experimental group (group 1 and group 2) for all three factors, $F 1: Z=-1.891, p=.030$, $\mathrm{r}=.20, \mathrm{~F} 2: \mathrm{t}(45)=3.216, \mathrm{p}=.002<.05, \mathrm{r}=.43, \mathrm{~F} 3: \mathrm{Z}=-$ 3.387, $\mathrm{p}=.001, \mathrm{r}=.35$ increased and this increase was statistically significant.

For question B8 regarding accuracy of positioning, while group 0 shows no difference between the three tests, group 1, t (20) $=-1.756, \mathrm{p}=.047<.05$ (1-tailed) $\mathrm{r}=$ 0.47 and group $2, \mathrm{t}(24)=1.794, \mathrm{p}=.043<.05$ (1-tailed), $\mathrm{r}$ $=0.34$, showed a statistically significant increase in their score between the intermediate (after the first visit) and the pre-test.

Similarly, for the correct placement, group 0 shows no difference between the three tests, but group $1, \mathrm{t}(20)=$ $1.705, \mathrm{p}=.029<.05, \mathrm{r}=0.47$, and group 2 ) $=2.326, \mathrm{p}$ $=.029<.05, r=0.43$, showed a statistically significant increase in their score between the intermediate and the pre-test (after the first visit). However, no significant difference is observed between post and intermediate control for any group.

For scenario C1, control group (group 0) did not show any difference between pre- and post-test for any of the justifications. For the experimental group (groups 1,2), however, two statistically significant changes in the justifications were observed: increase of the evolutionary reasoning, $\mathrm{z}=-2.513, \mathrm{p}=.012>.05, \mathrm{r}=.26$, and decrease of the creationist reasoning $\mathrm{z}=-4.343, \mathrm{p}=.00001<1 \%, \mathrm{r}$ $=.45$.

For the other three scenarios (C2, C3 and C4) the results of the statistical analysis in the cumulative score for each justification show that for the evolutionary reasoning there is no statistically significant difference between the three groups, $\mathrm{F}(2,65)=1,351, \mathrm{p}=.266>.05$, $\omega=.10$, while there are differences in both the intuitive reasoning, $F(2,65)=3,340, p=.042<.05, \omega=.25$ and the creationist reasoning $F(2,65)=15.04, p=.000<.05, \omega$ $=.54$.

With the help of the post hoc analysis, it is evident that the difference in the intuitive reasoning concerns groups 1 and 2, Games-Howell Sig. = .047<.05, namely Group 1 is showing a large decline against a very small increase in Group 2. For the creationist reasoning there are differences between groups 1 and 0 (Dunnett $t$ (2-sided) Sig. $=.000<.05$ ), and between groups 2 and 0 , Dunnett $t$ (2-sided) sig .002<.05). These differences are due to the drop of teams 1 and 2 against the practically stable score of group 0 .

\section{Discussion and Conclusion}

Our previous findings indicate that studying a controversial issue such as the acceptance of evolutionary theory in a multivariate fashion, using conceptual ecology as a theoretical lens to interpret the findings, is informative [6]. Students' restricted understanding of evolutionary theory is positively correlated with moderate acceptance of evolutionary theory, the same was recorded for religious practising and acceptance of 


\section{International Journal of Paleobiology \& Paleontology}

evolution does. They also, indicate the differences that exist from society to society and how socio-cultural factors such as the nature of religion as part of the conceptual ecology influence acceptance of evolution and have strong influence on evolution education. And how useful is the enrichment of the Conceptual Ecology with other factors, i.e. thinking dispositions or making students familiar with the scientific method. One good way to familiarize students and pupils with Science is by the visit of Museums and Science Centers. The latter seem to form a prominent base for the communication of science. The challenge for both pupils and teachers is to make learning enjoyable, so that they can successfully compete in today's crowded leisure-time marketplace. But apart from just being attractions for kids, science centers and museums also play another important role in the continuing education of teachers and provide the necessary knowledge, experience and material for making modern science appealing [26].

In the present paper it was assumed that evidence of Evolution like fossils can provide a suitable learning environment for the deeper understanding of TENS. Summarizing the results obtained from the statistical analysis we can conclude that the first visit caused a statistically significant increase in the understanding of the concepts of relative age of rocks, the change of environmental conditions over time, the importance of fossils in the understanding of Evolution and consolidating events such as massive extinction of species. As far as the chronological placement of major events in the Earth's history is concerned, the experimental group placed more accurately the events on the time scale after the first visit. Furthermore, there was an increase in the number of students of the experimental group that placed these events in the correct order. Finally, in scenario C1 (mammoth) students of this group when examined before and after the first visit, they were found to show a slight increase in their evolutionary reasoning and a decrease in the creationist reasoning.

Following the second visit of students and regarding the accuracy of the major events placement in chronological order, the experimental group 2 placed the facts even more accurately compared to previous two tests, but again this increase was not statistically significant. In this group the number of students who correctly ordered the events in relation to the mid-test also increased, but this increase was not statistically significant. Similar increases were also seen in Group 1, but this group did not participate in the second visit study. Consequently, it seems that the impact from the first visit is evaluated to be more important than the second visit, which seems to have had a positive effect but not as statistically significant as the first. For the three scenarios examined after the second visit, a statistically significant reduction of the creationist reasoning was observed after the two visits.

Taking all this into account, it becomes obvious that the level of understanding for the relevant supportive precursor concepts to TENS such as the relative age of fossils and rocks, the importance of fossils, the environmental variability, the mass extinction of species is much easier to improve. On the other hand, the adoption of evolutionary views to justify observations is much more difficult to enhance, obviously because it requires a greater degree of combinatorial thinking something that students are not at all familiar with.

Our findings show that intuitive perceptions towards TENS are potent and resilient to change. Students come to school having already formed, mainly alternative, perceptions of how the world works. These perceptions often differ from the accepted scientific model. Because they are configured in from the personal experience of each student, these perceptions are very much difficult to change [27]. Such misconceptions have been previously detected in students at all levels, and timely detection, eradication, and ultimately, replacement, should begin early and be a priority of science education programs and training programs for teachers at universities [28]. A positive result is that creationist perceptions are severely impaired and can be retreated significantly, when students come in contact with tangible testimonies and evidence such as fossils. It seems that contact with such tangible evidence of evolution is enough to troubleshoot students with alternative ideas, and make them, if not reject, at least to create doubts and prepare the grounds to be open in following the modes that science pursues. Also, making pupils more familiar with the age of major geological events, even when not completely convincing, they bring very close to awareness.

The visits improved the views, attitudes and perceptions of our students towards TENS and provided insight into the concepts that are needed for a better and deeper understanding of it. This became more than obvious when the corresponding chapter of the textbook was discussed after the second visit. The interest of the students who participated in the visits towards TENS was found to be much better and their participation from then on more than satisfactory. They also seemed to have a better understanding of the core features of TENS presented in the textbook and they showed a constant unconscious attempt to link what was presented to them 


\section{International Journal of Paleobiology \& Paleontology}

in the class with something they had already observed during their visits. These interventions were found to work, altogether, in multiple ways towards increasing the chances for a deeply-rooted learning experience.

\section{References}

1. Rutledge ML, Warden MA (2000) Evolutionary Theory, the Nature of Science \& High School Biology Teachers: Critical Relationships. The American Biology Teacher 62(1): 23-31.

2. National Academy of Sciences (US) (1998) Teaching about Evolution and the Nature of Science. Joseph Henry Press.

3. Nehm RH, Poole TM, Lyford ME, Hoskins SG, Carruth L, et al. (2009) Does the segregation of evolution in biology textbooks and introductory courses reinforce students' faulty mental models of biology and evolution? Evolution: Education and Outreach 2(3): 527-532.

4. Miller JD, Scott EC, Okamoto S (2006) Public Acceptance of Evolution. Science 313(5788): 765766.

5. Athanasiou K, Mavrikaki E (2013) CINS as a Tool for measuring Greek University Students' Evolution Knowledge - Differences between Novice and Advanced Students. International Journal of Science Education 18(2): 129-142.

6. Athanasiou K, Katakos E, Papadopoulou P (2012) Conceptual ecology of evolution acceptance among Greek education students: the contribution of knowledge increase. Journal of Biological Education 46(4): 234-241.

7. Thagard P, Findlay S (2010) Getting to Darwin: Obstacles to Accepting Evolution by Natural Selection. Science \& Education 19(6-8): 625-636.

8. Prinou L, Halkia L, Skordoulis C (2011) The Inability of Primary School to Introduce Children to the Theory of Biological Evolution. Evolution: Education and Outreach 4(2): 275-285.

9. Lucas AM (1971) The Teaching of Adaptation. Journal of Biological Education 5(2): 86-90.

10. Tal T, Morag $O$ (2007) School visits to natural history museums: Teaching or enriching? Journal of Research in Science Teaching 44(5): 747-769.
11. Gilbert J, Priest M (1997) Models and discourse: A primary school science class visit to a museum. Science Education 81(6): 749-762.

12. Spiegel AN, Evans EM, Frazier B, Hazel A, Tare M, et al. (2012) Changing Museum Visitors' Conceptions of Evolution. Evolution: Education and Outreach 5(1): 43-61.

13. Tsoukala E (2000) Remains of a Pliocene Mammut borsoni (Hays, 1834) (Proboscidea, Mammalia), from Milia (Grevena, W. Macedonia, Greece) 86(3): 165191.

14. Kerlinger FN (1973) Foundations of behavioral research: Educational, psychological and sociological inquiry. Holt Rinehart and Winston.

15. Abbott ML (2011) Understanding educational statistics using Microsoft Excel ${ }^{\circledR}$ and SPSS $®$. Hoboken, NJ: Wiley.

16. Campbell DT, Stanley J (1963) Experimental and quasi-experimental designs for research on teaching. In: Gage NL (Ed), Handbook of research on teaching, Chicago: Rand McNally, pp: 171-246.

17. Rutledge ML, Warden MA (1999) The Development and Validation of the Measure of Acceptance of the Theory of Evolution Instrument. School Science and Mathematics 99(1): 13-18.

18. Dodick J, Orion N (2003a) Introducing Evolution to Non-Biology Majors Via the Fossil Record: A Case Study from the Israeli High School System. The American Biology Teacher 65(3): 185-190.

19. Dodick J, Orion N (2003b) Measuring student understanding of geological time. Science Education 87(5): 708-731.

20. MacFadden BJ, Dunckel BA, Ellis S, Dierking LD, Abraham Silver L, et al. (2007) Natural History Museum Visitors' Understanding of Evolution. Bio Science 57(10): 875-882.

21. Bishop BA, Anderson CW (1990) Student conceptions of natural selection and its role in evolution. Journal of Research in Science Teaching 27(5): 415-427.

22. Brumby M (1979) Problems in learning the concept of natural selection. Journal of Biological Education 13(2): 119-122. 


\section{International Journal of Paleobiology \& Paleontology}

23. Brumby MN (1984) Misconceptions about the concept of natural selection by medical biology students. Science Education 68(4): 493-503.

24. Evans EM, Spiegel AN, Gram W, Frazier BN, Tare M, et al. (2010) A conceptual guide to natural history museum visitors' understanding of evolution. Journal of Research in Science Teaching 47(3): 326-353.

25. Field AP (2009) Discovering statistics using SPSS: (and sex, drugs and rock " $n$ " roll), $3^{\text {rd }}$ (Edn.), Los Angeles: SAGE Publications.
26. Owens SR, Lecrubier A, Breithaupt H (2002) A day at the museum: science centres and museums play an increasingly important role in bringing science and technology to the public. EMBO Reports 3(6): 506510.

27. Driver R (1983) The pupil as scientist? Milton Keynes [England]: Open University Press.

28. Yates TB, Marek EA (2015) A Study Identifying Biological Evolution-Related Misconceptions Held by Prebiology High School Students. Creative Education 6(8): 811-834. 